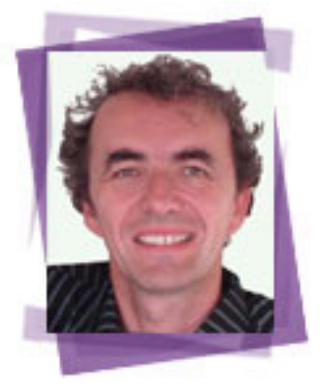

\title{
The Translation Crowd
}

\author{
Michael Cronin \\ Dublin City University
}

\begin{abstract}
Over the last few decades, translation studies have evolved from the linguistic turn of the 1960s and 1970 s to the cultural turn of the 1980 s and 1990 s to the technological turn taken today. A quick review of the historical basis for today's approach reveals its core concept, ubiquitous computing, as well as its implications for how content should be treated and the consequences for the next generation of students. Prosumption, post-print literacy and pluri-subjectivity are key concepts to understanding the future of the discipline.
\end{abstract}

\section{Keywords}

technological turn, ubiquitous computing, crowdsourcing, wiki-translation, social networking, gist translation, prosumption, post-print literacy, pluri-subjectivity

\section{Introduction}

Accounts of translation studies often turn to turns. The 1960s and 1970s were said to be characterised by the linguistic turn while the 1980s and 1990s saw the emergence of the cultural turn in translation studies scholarship (Snell-Hornby, 2006). These turns were largely determined by developments in adjacent disciplines - linguistics, cultural theory, history - that appeared to offer new or interesting perspectives for translation scholars. At the close of the first decades of the noughties, it is possible to point to a new twist or turn in the study of translation, what we might term this time the «technological turn». The technological turn is driven not by theoretical developments in cognate areas of inquiry, though it can be informed by them, but is an emergent property from new forms of translation practice. That is to say, the turn in question is the result of significant shifts in the way in which translation is carried out in the contemporary world. These shifts demand that conventional understandings of what constitutes translation and the position of the translator be systematically re-examined.

\section{Back to the Origins}

In order to consider what the nature of the technological turn might be it is first necessary to return the founding credo of media studies as articulated by Marshall McLuhan. McLuhan famously argued that what mattered most about new media was not the content they carried but the medium itself (McLuhan, 1964/2001). Whereas a great deal of early debate had focused on television as a corrupter of youth because of the violent or «decadent» nature of its content, McLuhan argued that the real message of television lay not in what it carried but in what it was. The ability to beam images from around the globe 
into people's private homes within hours and eventually within microseconds of the events happening was infinitely more important in its effect (the creation of imagined global communities of spectatorship) than what was actually shown on these images. Footage of the Apollo moon landing in private homes did much more to change the notion of what it was to inhabit the earth than to advance in any real sense popular understanding of what it might be to live on the moon. Of course, television was only one of the many media throughout history where the medium itself is the most important message.

Francis Bacon writing in his Novum Organum in 1620 claimed that movable-type printing had so changed the world that «no empire or sect seems to have exercised a greater power and influence on human affairs» (Bacon, 1863: 129). The fruits of literacy, which had formerly been the preserve of a cultivated elite, were now made available to much larger numbers of people. According to one set of estimates, the number of books published in the half century after Gutenberg's invention were equal to the total output produced by European scribes during the previous one thousand years (Clapham, 1957: 37 ). By the end of the $15^{\text {th }}$ century, nearly 250 towns in Europe had print shops and 12 millions volumes had already appeared in print. Knowledge was miniaturised (no cumbersome Codices), made portable, privatised (available to individuals of modest means and not just to institutions and the wealthy) and multiplied (more words on smaller pages in many more copies) by the new intellectual technology that was the printing press (Eisenstein, 1980). As Nicholas Carr has pointed out, citing the examples of the map and the clock, intellectual technologies shape and articulate new world views:

Every intellectual technology, to put it another way, embodies an intellectual ethic, a set of assumptions about how the mind works or should work. The map and the clock shared a similar ethic. Both placed a new stress on measurement and abstraction, on perceiving and defining forms and processes beyond those apparent to the senses. (Carr 2010: 45)

Seeing time as an objectively measurable quantity in a timepiece is a radically different experience from a subjective notion of time incorporated into a task which takes as long as it will take but has no reference to «external» time. A city dweller moving through streets familiar from birth will experience it very differently at a spatial and cognitive level from a tourist armed with a map. So if the medium is indeed the most important message to retain from human technical advances and our intellectual technologies - the tools that we employ to extend or support our mental powers - embody an intellectual ethic, what are we to conclude about the implications of these intellectual ethics for the development of our thinking about translation?

When Alister McGrath set about telling the story of the genesis of the most famous translation in the English language, the King James Bible or the Authorized Version, he discusses Erasmus, Luther, early pioneers such as Wycliffe and Tyndale, the Reformation insistence on the importance of the vernacular but the very first chapter is devoted to «Unknown to the Ancients: The New Technology» (McGrath, 2000: 5-23). For McGrath, the new technology of printing implied an intellectual ethic of mobility which would be hugely significant for the role of translation in religious and political history. In the early $16^{\text {th }}$ century vernacular translations of the Bible were prohibited in England but as McGrath notes:

\footnotetext{
It was one thing to block the production of such a Bible in England. What would happen if an English translation of the Bible were to be produced abroad, and smuggled into England? The very idea of such a Bible was deeply upsetting to the English elite at this time. The development of the technology of printing in Europe meant that there was a very real threat of someone producing such a Bible as business venture, aiming to make money out of it. What could be done to stop this? As events proved, this much-feared development would not take place until the 1520 s. As expected it proved formidably difficult to detect and prevent such an importation. (22-23)
}

The medium of printing becomes part of the message of translation. Prolific, mobile, accessible, the translated products of the printing press will provoke religious upheaval in country after country. A similar scenario will accompany the dissemination of the translated ideas of the $18^{\text {th }}$ century Enlightenment, $19^{\text {th }}$ century socialism or $20^{\text {th }}$ century liberalism (Delisle and Woodsworth 1995). In other words, when Holmes in his celebrated «map» of translation studies speaks of medium-restricted theories he misses a crucial 
dimension to what the relationship is between medium and message in translation. For Holmes, mediumrestricted theories can be subdivided into theories of translation done by machines or humans. Further subdivisions are possible depending on whether we are speaking of automated translation or of a machine assisting a human translator. Other possible divisions are whether the human translation is written or spoken and whether the spoken translation or interpreting is consecutive or simultaneous (Holmes in Venuti, 2004: 180-92). The notion of 'medium' thus construed is as a kind of classificatory aid, a way of expressing how contents are differently transmitted. However, it is arguable that 'mediumrestriction' is more than a simple heuristic device, a convenient handle for defining content delivery, that the definitional possibilities of a medium challenge notions of translation invariants which remain constant across different media.

\section{Reaching the Ubiquity}

One of the most notable developments in the last two decades has been the shift from stand-alone PCs, located at fixed work stations to the spread of distributed computing in the form of laptops, wireless PDAs, mobile phones with internet connectivity and so on. It is not only humans but their machines which are on the move. As the British sociologists Dennis and Urry put it, «This trend in distributed computing is developing towards a shift to ubiquitous computing where associations between people, place/space, and time are embedded within a systemic relationship between a person and their kinetic environment.» (Dennis and Urry, 2007: 13). Ubiquitous computing sometimes referred to as the «third wave of computing» is one «whose cross-over point with personal computing will be around 2005-2020» and which may become «embedded in walls, chairs, clothing, light switches, cars - in everything» (Brown and Weiser, 1996). Greenfield has talked of «everyware» where information processing is embedded in the objects and surfaces of everyday life (Greenfield, 2006: 18). The probable social impact of everyware can be compared to electricity which passes invisibly through the walls of every home, office and car. The transition from fixed locations of access to increased wireless presence coupled with the exponential growth of internet capability means that greatly augmented information flows become part of an information-immersive environment.

A consequence of the emergence of ubiquitous computing is that computing capacity dissolves into the physical surroundings, architectures and infrastructures. Marcos Novak has developed the term 'transArchitecture' to signify «a liquid architecture that is transmitted across the global information networks; within physical space it exists as an invisible electronic double superimposed on our material world» (Novak, 2010). William Mitchell in the 1990s had already spoken of a «city of bits» where the combination of physical structures in urban spaces with the electronic spaces and telematics would be known as «recombinant architectures» (Mitchell, 1995: 46-105). It is difficult to conceive of the transarchitectural in contemporary urban spaces without factoring in the multilingual. That is to say, part of the thinking about next-generation localization and globalization is precisely the role that translation will play in the era of distributed, ubiquitous computing. It is possible to conceive of buildings - government offices, university halls of residence, transport hubs - which would be multilingually enabled. A hand-held device such as a mobile phone would allow the user to access relevant information in the language of his or her choice. Thus, rather than the static and serial presentation of information in a limited number of languages, such a development would allow for a customised interaction with the language user with the possibility for continuous expansion in languages offered and information offered.

\section{The New Approach}

Advances in peer-to-peer computing and the semantic web further favour the transition from a notion of translation provision as available in parallel series to translation as part of a networked system, a 
potentially integrated nexus. In other words, rather than content being rolled out in a static, sequential manner (eg separate language information leaflets at tourist attractions), translated material would be personalised, user-driven and integrated into dynamic systems of ubiquitous delivery. The semantic web points up the potential for forms of collaborative, community translation that are already a conspicuous feature of translation practice in late modernity. In the online social network off Second Life almost threequarters of the 900,000 monthly users are non-English naïve speakers. The site has been localized by volunteer translators into German, French, Japanese, simplified Chinese, Turkish, Polish, Danish, Hungarian, Czech, Korean and Brazilian Portuguese. The volunteer translators were involved not only in translation but in terminology management and in editing and testing localized versions (Ray 2009). Facebook has also used a crowdsourcing model to translate contents into languages other than English and fan translation is increasingly widespread in everything from the translation of Japanese anime to Korean soap operas (O'Hagan 2009: 94-121). The advent of «wiki-translation» indicates that the rapid dissemination of online social networking practices not only generates new translation needs but has farreaching consequences for the profession of translator in an age of globalization. Interactive, usergenerated content which is a core feature of Web 2.0 is now informing translation practice and in this context, translation consumers are increasingly becoming translation producers. The growing prevalence of web-based machine translation services in the guise of Google Translate and others call into question the traditional status of the translator with norms of professional translator training coming under pressure from collaborative forms of translation practice mediated by new translation technologies such as the Google Translator Toolkit. As regards the visibility of the translator, the move towards web-based MT services would appear to render invisible the labour of translation whereas the development of wikitranslation would indicate the making visible of the demands of translation for large groups of global users. What is especially apparent in the emergence of the interactive web is that a new medium is not simply an addition to the old one. The traditional media, vectors of translation such as the printing press, are profoundly re-shaped. As Nicholas Carr observes:

When the Net absorbs a medium, it re-creates that medium in its own image. It not only dissolves the medium's physical form; It injects the medium's form with hyperlinks, breaks up the content into searchable chunks, and surrounds the content with the content of all the other media it has absorbed. All these changes in the form of the content also change the way we use, experience, and even understand the content. (Carr 2010: 90)

The bidirectionality of Web 2.0, a characteristic of the medium, has begun to determine the nature of translation at the outset of the $21^{\text {st }}$ century with the proliferation of crowd-sourced translation or open translation projects such as Project Lingua, Worldwide Lexicon, Wiki Project Echo, TED Open Translation Project and Cucumis. The changes in the form of the content have begun to change the way content is not only used, experienced or understood but translated. In pointing to the emergence of crowd-sourced or wiki-translation, it is possible to define three characteristics of this medium-driven change with implications for thinking about translation:

\subsection{Translation Prosumption}

Translation debates in recent decades have returned again and again to the question of source or target language orientation in translation. Dynamic and formal equivalence, semantic and communicative translation, foreignization versus domestication, skopos theory, Descriptive Translation Studies, have all been drafted into the polemic over the most appropriate forms of orientation. Implicit in all these models, however, is the notion of an agent who produces a translation for consumption by an audience. It is a production-oriented model of externality. In the case of crowd-sourced translation, however, it is the potential audience for the translation that does the translation. The model is a consumer-oriented model of internality. The consumer becomes an active producer or prosumer. It is no longer a question of the translator, for example, projecting a target-oriented model of translation on to an audience but the audience producing their own self-representation as a target audience. Such a shift makes problematic 
traditional distinctions which generally presuppose active translation agents and passive or unknowable translation recipients.

\subsection{Post-print translation literacy}

In a study by a team of German researchers on the behaviour of web users, they concluded that most web pages were viewed for ten seconds or less. Even pages with plentiful information and many links were only viewed for an extremely brief period (Weinreich, Obendorf, Herder and Mayer, 2008: 1-26). An Israeli company Clicktale which supplies software for analyzing how people use corporate web pages assembled data on the behaviour of a million visitors to sites maintained by its corporate clients. They found that in most countries people spend between 19 and 27 seconds looking at a web page before moving on to the next one and this includes the time necessary for the page to load into the browser's window (Clicktale, 2008). In effect, the Internet encourages a shift from steady, cumulative, linear reading to a form of accelerated power browsing. As translation has a visceral link to prevailing paradigms of literacy, then as these changes, we must expect translation to change in nature. In a culture of high print literacy with an emphasis on ordered, linear progression through a text, it is only to be expected that translation pedagogy will place a particular emphasis on the careful, cumulative reading of text and the production of texts answerable to the norms of high print literacy. However as we move from a technological world defined by the printing press to one defined by the electronic computer, reading practices and literacy norms inevitably change. As Colin Cooper noted in a blog on Translation Crowdsourcing, crowdsourcing is particularly effective when «initial quality is not the top priority» (Cooper, 2009). The emergence of gist translation or the acceptance of lower quality translation output must be related to the shifting reading and literacy norms as readers of web-bases material have a significantly different approach to their engagement with text, namely, instrumentalised, non-linear and greatly accelerated. Peer-pressure can, of course, be a powerful incentive to improve quality through collaborative correction but the more important point is that as literacy expectations evolve so too will translation practices.

\subsection{Translation and Pluri-subjectivity}

Traditionally, governments have been fearful of crowds. When Baron Haussmann set about the reconstruction of nineteenth-century Paris he was ever mindful of how the design of his streets might facilitate the control of the revolutionary mob (Schnerb 1993). But like flashmobs, crowds turn up when and where you least expect them. It is in the context of the subversive potential of the crowd that is useful to locate particular crowdsourcing practices. Whether it is volunteer translators translating alternative media sources from citizen journalists around the world for Project Lingua (http://globalvoicesonline.org/lingua) or translators working to produce translated versions of the documents released on the controversial WikiLeaks site, the politicisation of translation through collective volunteer action is present and growing. At one level, it is possible to locate these translation practices in the type of self-reflexive political agency at work in organisations like Babels (Boéri, 2008: 21-50). At another, what is implicitly contested in these practices is a conception of machine-human interaction in translation as fundamentally dehumanising. If a tendency in localisation discourse has been to accentuate the role of automation in translation activity and to minimise the intervention of the human agent, what we are witnessing in these crowdsourcing initiatives is a reinvestment of translation technology by the human, a strategic use of technical resources to further human concerns or agendas. In a sense, what is emergent in the practice is a version translation technology as a tool of conviviality and an instrument of human political intervention. Implicit in such a representation of translation is a move away from the monadic subject of traditional translation agency - Jerome alone in the desert - to a pluri-subjectivity of interaction. 
What prosumption, post-print literacy and pluri-subjectivity point to is the need for translation scholars to attend carefully to the growing implications of the technological turn in translation studies.

\section{References}

Francis Bacon (1863), Novum Organum, tr. James Spedding, Robert Leslie Ellis, and Douglas Denon Heath in Francis Bacon, The Works, Vol. VIII, Boston: Taggard and Thompson.

Boéri, Julie (2008) 'A Narrative Account of the Babels vs. Naumann Controversy. Competing Perspectives on Activism in Conference Interpreting', The Translator, 14, 1, 21-50.

Brown J.S. and Weiser M. (1996) 'The Coming Age of Calm Technology'. Available at: http://www.ubiq.com/hypertext/weiser/acmfuture2endnote.htm (accessed 18 July 2010).

Carr, Nicholas (2010) The Shallows, London: Atlantic.

Clapham, Michael (1957) 'Printing', in A History of Technology: From the Renaissance to the Industrial Revolution c.1500-c.1750, vol. 3, Oxford: Oxford University Press.

Clicktale (2008) 'Puzzling Web Habits across the Globe', Clicktale Blog, July 31. Available at http://www.clicktale.com/2008/07/31/puzzling-web-habits-across-the-globe-part-1 (accessed 7 August 2009).

Cooper, Colin (2009) 'Is Translating Crowdsourcing Unethical?' Available at: http://colincooper.net/?p=31 (accessed 23 September 2010).

Delisle, Jean and Woodsworth, Judith (1995) Translators in History, Amsterdam: John Benjamins. Dennis, Kingsley and Urry, John (2007) 'The Digital Axis of Post-Autombility'. Department of Sociology, Lancaster University, 1-74. Available at: http://www.kingsleydennis.com/The\%20Digital\%20Nexus\%20of\%20Post-Automobility.pdf (accessed 5 September 2010).

Eisenstein, Elizabeth L. (1980) The Printing Press as an Agent of Change, Cambridge: Cambridge University Press.

Greenfield, A. (2006) Everyware: The Dawning Age of Ubiquitous Computing, Berkeley CA: New Riders. McGrath, Alister (2000) In the Beginning: The Story of the King James Bible, London: Hodder and Stoughton.

McLuhan, Marshall (2001) Understanding Media: The Extensions of Man, $2^{\text {nd }}$ edition, London: Routledge (first edition 1964).

Mitchell, William (1995) The City of Bits, London: MIT Press.

Novak, Marcos (2010) 'The Meaning of Transarchitecture'. Available at http://www.fenom.com/network/2010/03/05/the-meaning-of-trans-architecture-marcos-novak/ (accessed 1 October 2010). 


\section{>> revista tradumàtica}

Traducció i Tecnologies de la Informació i la Comunicació

Número 08: Localització i web : desembre 2010 :

http:/www.fti.uab.cat/tradumatica/revista : ISSN: 1578-7559

O’Hagan, Minako (2009) ‘Evolution of User-generated Translation: Fansubs, Translation Hacking and Crowdsourcing', Journal of Internationalisation and Localisation, 1, 1, 94-121.

Ray, Roger (2009) Crowdsourcing: Crowd wants to help you reach new markets, Romainmôtier: Localization Industry Standards Association.

Schnerb, Robert (1993) Le XIXè siècle, Paris: PUF.

Snell-Hornby, Mary (2006) The Turns of Translation Studies, Amsterdam: John Benjamins.

Weinreich, Harald, Obendorf, Hartmut, Herder, Eelco and Mayer, Matthias (2008) 'Not Quite the Average: An Empirical Study of Web Use', ACM Transactions on the Web, 2, 1, 1-26.

Venuti, Lawrence (2004) The Translation Studies Reader, London: Routledge. 